\title{
Awareness of Infection Control among Dental Students and Interns
}

\author{
Barsha Ghimire, ${ }^{1}$ Suresh Chandra' \\ 'Department of Prosthodontics, Kantipur Dental College, Basundhara, Kathmandu, Nepal.
}

\section{ABSTRACT}

Introduction: Disease transmission can occur through direct contact, blood, oral fluids, or other secretions and indirect contact with contaminated instruments, operatory equipment, or objects. Prevention of cross contamination helps in reducing the infection. The level of education of the students, and their knowledge about the infection control directly relates to the patient care. The current study aims to determine the level of knowledge and infection control procedures among dental students in a clihnical practice.

Methods: This was a cross-sectional study with a self-administered questionnaire comprised of 18 open and close-ended questions related to infection control and prevention. Answers of the questions were analysed by SPSS version 20.

Results: Among the students included, 53 (36.8\%) participants were intern, 31 (21.5\%) from fifth year, 31 (21.5) from fourth year and 29 (20.1) were third year. Performance satisfaction shows that the students were fairly satisfied with their performance. When students were asked to rate the implementation of infection control policy in their clinical practice $1(0.7 \%)$ were very good, $74(51.4 \%)$ were fair, $44(30.6 \%)$ were good are while $25(17.4 \%)$ were poor to implement infection control policy in their practice.

Conclusions: The level of knowledge and practice of infection control measures was poor among dental students. The attitude towards infections control measures was positive, but a greater compliance was needed. Formal class and examination may help improve knowledge and clinical practices.

Keywords: dental students; infection control; sterilization.

\section{INTRODUCTION}

Infection and cross contamination is a major problem for health care system in many countries. Infection control has gained much attention especially in dentistry after the introduction of Human Immunodeficiency Virus (HIV) infections in 1980s, and reports of contamination of six patients by dentists. ${ }^{1}$ Disease transmission can occur through direct contact blood, oral fluids, or other secretions; indirect contact can occur with contaminated instruments, operatory equipment, or environmental surfaces; or contact with contaminants that are airborne. ${ }^{2}$

Dental health personnel, students and assistants are at high risk of exposure to cross-infection with pathogens.
Dental institutes are responsible for providing appropriate infection control measures to establishment of safer working conditions. ${ }^{3-5}$ This is the reason why dental education can play an important role in the training of dentists to adopt adequate attitudes related to infection control. ${ }^{6,7}$

This study was done to assess the awareness of infection control and prevention among different level of dental students.

Correspondence: Dr. Barsha Ghimire, Department of Prosthodontics, Kantipur Dental College, Basundhara, Kathmandu, Nepal. Email: b28barsha@gmail.com, Phone: +977-9841229734. 


\section{METHODS}

This cross-sectional study was conducted at Kantipur Dental College (KDC) and Hospital, Kathmandu Nepal in August 2017. Ethical approval was taken from KDCIRC. Written consent was taken from participants. All the clinical students from third, fourth, final year and interns were included in the study. Convenience (nonprobability) sampling method was used and sample size of 118 was calculated using following formula:

$$
\begin{aligned}
& \underline{Z} \frac{\underline{2} \times P(1-P)}{e^{2}} \\
& \text { Sample Size }=\frac{}{1+\underline{Z^{2}}-\underline{x}-\frac{P(1-P)}{e^{2}} \cdot \frac{N}{117.01}} \\
& =117.01
\end{aligned}
$$

Where Population size $(N)=150$; Confidence level $(\%)=95 ; P=0.333^{8}$ with Margin of error $(e)=0.04$

A structured questionnaire was developed from previously validated items ${ }^{7,8}$ with few modifications to suit the population and 18 close-ended questions comprised of knowledge of infection control and their implementation in clinical practice. The questionnaire collected data on knowledge pertaining to infection control procedures, sterilization, disinfection of instruments, occupational hazards and immunization, etc. The dental students were asked to fill out the questionnaire in the lecture halls without consultation discussion in 15 minutes. Out of 150 students those who did not submit the questionnaire were excluded from the study. The sample 144 comprised of 29 third year, 31 fourth year, 31 final year students and 53 interns. The mean score was calculated gender wise and based on the year of study and comparisons were drawn.

Statistical package for social science (SPSS) version 20.0 was used for the data entry and analysis. The data were presented and the outcomes were analysed using Chi-square test. P-value was calculated under the predetermined level of significance of 0.05 at the confidence interval of $95 \%$.

\section{RESULTS}

In the present study, out of 150 questionnaires distributed, only 144 students responded out of which $28(19.4 \%)$ were male and $116(80.6 \%)$ were female (Figure 1).

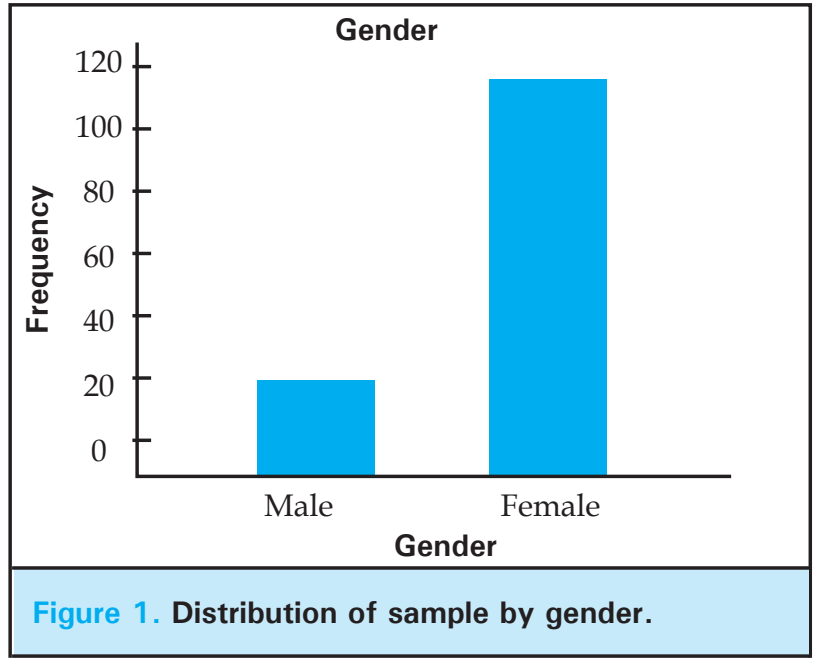

Among the students included, 53 (36.8\%) participants were intern, 31 (21.5\%) from fifth year, 31 (21.5\%) from fourth year and $29(20.1 \%)$ were third year (Figure $2)$.

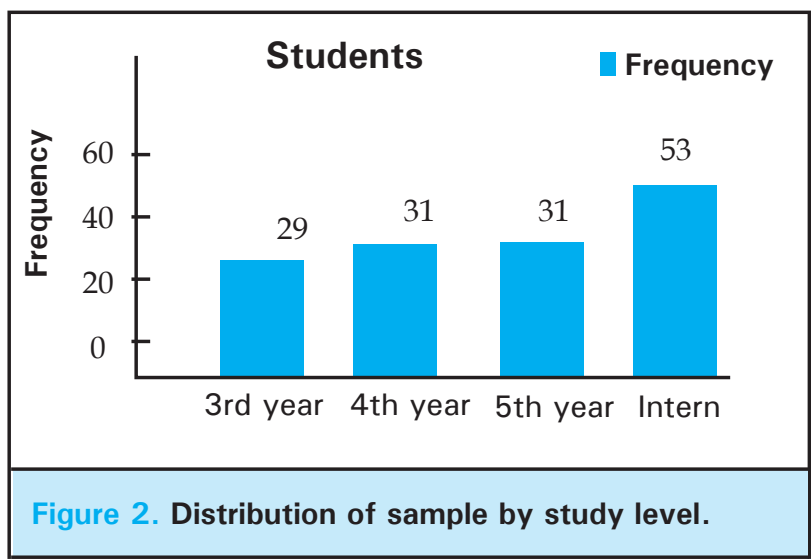

Performance satisfaction shows that the students were fairly satisfied with their performance.

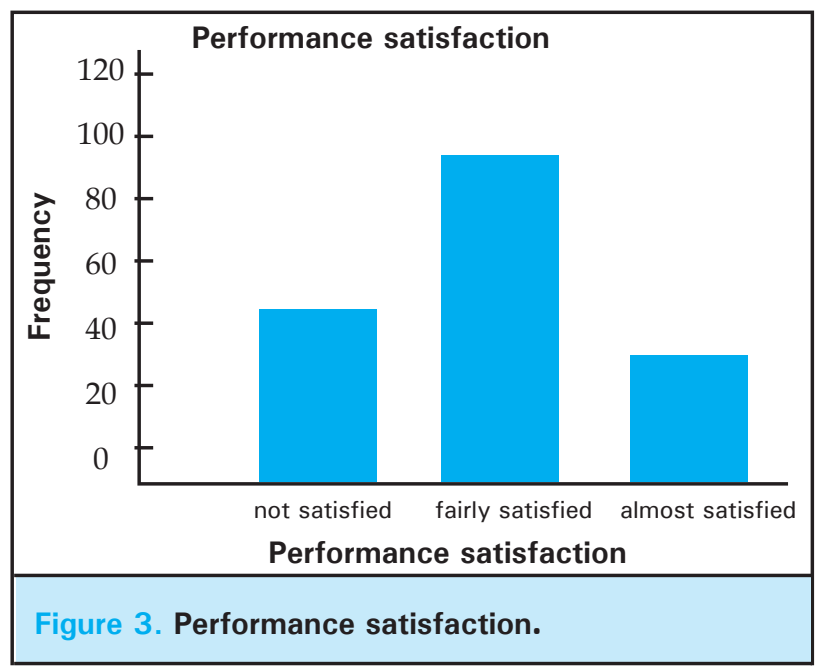


In response to question about their knowledge in infection control in prosthodontics, it most response were fair, while few had good idea (Figure 4).

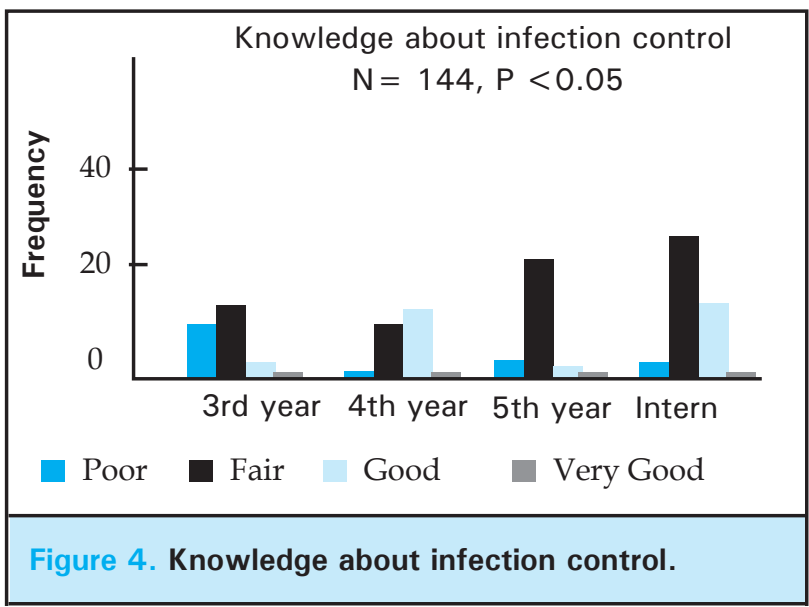

When students were asked to rate the implementation of infection control policy in their clinical practice, $51.4 \%$ were fair, $30.6 \%$ are good while $17.4 \%$ were poor to implement infection control policy in their practice (Figure 5).

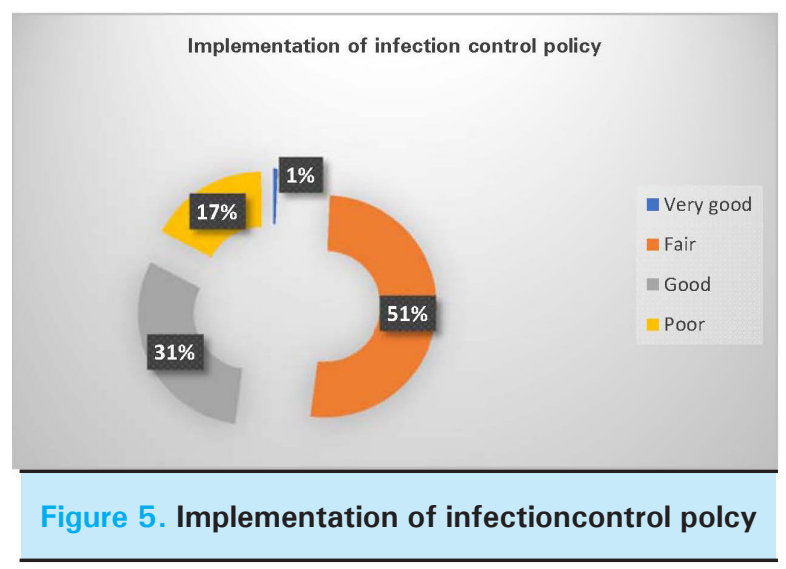

\section{DISCUSSION}

Dental students and other health care workers face the risk of occupational exposure to blood borne viruses such as the HIV, Hepatitis B Virus and Hepatitis C virus. Infections can me transmitted in dental practice through dental impressions, casts, trial and final prosthesis.9,10 So proper infection control measures should be applied to prevent cross infection to patients, dental personnel and laboratory workers. ${ }^{11}$
When the study about the infection control measures was done, there was no significant difference in the knowledge about the infection control among male and female students. The present study reveals that the level of knowledge was highest among interns followed by fifth year students. Implementation of infection control policy was found to be high among interns followed by third year students. On performance satisfaction females were found to me more fairly satisfied than males.

Despite the low response rate, this study exposed several potential limitations should take into consideration. First, the subjective responses (i.e. based on students' selfassessment) rather than being provided under academic supervision in a clinical environment, and therefore the results may not necessarily fully reflect students' real knowledge and daily professional practice. Second, the number and the way of questions cannot reflect the real knowledge and practice of the respondents. Nevertheless, the number of questions was kept to a minimum to improve the response rate, which appeared to work well. Finally, the data represented in this study were for one dental school, not the entire country. However, despite these limitations, this study provides some important information about dental students' knowledge, opinions, and practices regarding infection control in the dental environment.

\section{CONCLUSIONS}

Evaluating the results of previously conducted studies the level of awareness of infection control measures was poor among dental students. The attitude towards infectious control measures was positive, but a greater compliance was needed. Continuous education programs, practical lessons on sterilization procedures, use of barrier protection and infection control training, can complete improving the compliance of the dental students. The findings should alert dental educators about the importance of educating their students clearly and comprehensively about infection control measures. Formal class and examination may help improve both knowledge and clinical practice.

\section{ACKNOWLEDGEMENTS}

We would like to acknowledge all the participants of Kantipur dental college.

\section{Conflict of interest: None.}




\section{REFERENCES}

1. Khanghani BM, Jamali Z, Azar FP, Behzad MN, Aghdash SA. Knowledge, attitude, practice, and status of infection control among Iranian dentists and dental students: A systematic review. J Dent Res Dent Clin Dent Prospect. 2013;7(2):55-60. [PubMed | Full Text | DOI]

2. Alshiddi IF. Attitude and awareness of dental students and interns toward infection control measures in prosthodontic clinics. Dental, oral and craniofacial research. 2015;1:4;116-20. [Full Text]

3. Halboub ES, Al-Maweri SA, Al-Jamaei AA, Tarakji B, Al-Soneidar. Knowledge, attitudes, and practice of infection control among dental students at Sana's University, Yemen. J Int Oral Health. 2015;5:15. [PubMed | Full Text]

4. Shooriabi M, Gilavand A, Emam SA. Evaluating the awareness and performance ratio of dental assistants working in dentistry centers of the city of ahvaz in southwest Iran, about infection control. Int Jounal of Advanced Biotechnology and Research. 2017;7:151-6. [Full Text]

5. Abreu MH, Lopes-Terra MC, Braz LF, Rímulo AL, Paiva SM, Pordeus IA. Attitudes and behavior of dental students concerning infection control rules: A study with a 10-year interval. Braz Dent J. 2009;20(3):221-5. [PubMed $\mid$ Full Text]

6. Alolah L, AlSaadoun D, AlHazza'a H, AlJubair A, Alenazi B, AlShammery D, AlGhamdi W. Awareness and Practice of infection control among selected sample of dental students in Saudi Arabia. International Journal of Innovative Research in Medical Science. 2017;2:8. [Full Text]
7. Al-Essa NA, AlMutairi MA. To what extent do dental students comply with infection control practices? The Saudi Journal for Dental Research. 2017;8:67-72. [Full Text]

8. Ehsani M, Tabarsi T, Abesi F, Mesgarani A, SMohammadi M. Knowledge and attitude of dental students towards infection control in Babol dental school. Journal of Dentomaxillofacial Radiology, Pathology and Surgery. 2013;2:3. [Full Text]

9. Ebrahimpour A, Pakravan AH, Nezhad MY, Alipour N, Saravi ME, Rahbar F, Khatam ZS. Knowledge and performance of dental students with regard to infection control guidelines in dental school of Mazandaran university of medical Sciences in 2015. International Journal of Medical science and Health Sciences. 2016;5;8:298-304. [Full Text].

10. Mohiuddin S, Dawani N. Knowledge, attitude and practice of infection control measures among dental practitioners in public setup of Karachi, Pakistan: Cross-sectional survey. J Dow Uni Health Sci Karachi. 2015;9;1:3-8. [Full Text].

11. Al-anesi MS, Alhajj MN, Al-Basmi AA. Compliance of dental students toward infection control in dental teaching hospital at Thamar University - Yemen. Braz Dent Sci. 2017;20:1. [Full Text] 